\title{
NICKEL AS AN ALTERNATIVE AUTOMOTIVE BODY MATERIAL
}

\author{
T. Joseph Sahaya Anand \\ Department of Engineering Materials, Faculty of Manufacturing Engineering, \\ Universiti Teknikal Malaysia Melaka, \\ Durian Tunggal, 76100 Melaka, MALAYSIA \\ Email: anand@utem.edu.my
}

\begin{abstract}
The study of the thermal, chemical and mechanical properties of pure nickel as an alternative automotive body material is presented in this paper. Current automotive components mainly use steel as the body material. Due to the increasing demand for high performance and related issues, interest is moving towards alternative materials to steel. The hardness values of both heat-treated and non-heat treated pure nickel do not change after annealing; the hardness values are in the range of 118 to $123 \mathrm{HV}$. As the annealing temperature increases, the ultimate tensile strength, yield strength and Young's modulus decrease, which indicates that the ductility increases. The highest ultimate tensile strength of pure nickel at $300^{\circ} \mathrm{C}$ annealed temperature is $758.78 \mathrm{MPa}$. $\mathrm{X}$-ray diffraction (XRD) studies confirmed pure nickel as a face centred cubic (FCC) structure with a lattice constant measured as $0.3492 \mathrm{~nm}$ for the unannealed sample, which increases to $0.3512 \mathrm{~nm}$ for the annealed samples. The corrosion rate of both annealed and non-heat treated pure nickel is in the range of 0.0266 to $0.048 \mathrm{~mm} /$ year.
\end{abstract}

Keywords: Alternating material, nickel, annealing, corrosion resistance.

\section{INTRODUCTION}

Due to the increasing demand for high-quality exterior panels, better functional properties and lower weight in the automotive industry, much research has been conducted to find an alternative to the existing automotive body material; steel. One of the requirements of an alternative automotive body is weight reduction. This is because the weight of the automotive body will ultimately affect energy consumption. Every $56.69 \mathrm{~kg}$ of weight reduction results in a fuel economy gain of $0.09-0.21 \mathrm{~km}$ per litre. Therefore, lightweight materials are necessary to achieve fuel efficiency. Cui, Wang, and $\mathrm{Hu}$ (2008) stated that the automotive body and interior account for approximately $40 \%$ of the weight of an automobile. Therefore, automotive body materials have changed from steel to aluminium. However, conventionally the weight of the steel is greater than that of aluminium and the cost of steel is lower than aluminium. Apart from the weight of the material used for an automotive body, its mechanical properties are also important for increasing performance. Edwards (2004) stated that materials with properties of high specific stiffness and strength should be used for highly efficient lightweight load bearing structures. Whereas steel sheets with high strength and strain and transformation-induced plasticity should be used for body panels. The properties of alloy steel allow deep drawing; provide resistance to denting and offer the opportunity of using a lighter gauge in order to reduce vehicle weight. The material used in an automotive body should have the properties of high fracture toughness, which provides the capability of absorbing energy in the case of high-speed crashes. 
Klarstrom (2001) stated that nickel and nickel-based alloys are important to modern industry because of their ability to withstand a wide variety of severe operating conditions involving corrosive environments, high temperatures and high stress. Nickel, a transition metal is ductile and tough because it possesses a face-centred cubic crystal structure up to its melting point. It is used for making stainless steel, low alloy steels and cast iron, etc. It is widely used in variety of applications: food-processing equipment, chemical shipping drums, battery manufacture, aircraft, gas turbines, caustic handling equipment and piping. Of the galvanic series of metals, nickel is one of least active elements, which means that the tendency of nickel to corrode is low. According to Rebak, Dillman, Crook, and Shawber (2001), nickel has good resistance to corrosion in the normal atmosphere, natural freshwater and deaerated non-oxidising acids and has excellent resistance to corrosion by caustic alkalis. Lee, Woo, Lee, and Han (2008) stated that the automotive body must fulfil mechanical performance requirements, such as deflection, stiffness and strength, in an extensive number of structural design considerations and components. Steel is the traditional automotive body material; however, the steel needs to be coated due to its corrosion potential when exposed to moisture (Davies, 2003). In this research, the thermal properties of pure nickel were obtained by annealing with different temperatures. Various tests have been conducted to obtain the mechanical, chemical, structural and other properties of pure nickel. The testing includes: tensile tests, microhardness tests, corrosion tests, structural analysis by using X-Ray Diffraction (XRD) and composition and morphology studies by scanning electron microscope (SEM) and Energy-dispersive X-ray (EDX) spectroscopy. This work presents comparative data of the mechanical and chemical properties of pure nickel and samples annealed at 300,500 and $700{ }^{\circ} \mathrm{C}$.

\section{EXPERIMENTAL PROCEDURES}

The characterisation of pure nickel is studied as an alternative automotive body material. The processes involve heat treatment, during which the annealing of pure nickel at various temperatures is performed, followed by mechanical and corrosion tests. Annealed and unannealed samples were prepared to dimensions according to the international ASTM and ASE standards (Kuroda, Kawasaki, Yamamoto, Hiromoto, \& Hanawa, 2005). According to Tillack, Manning, and Hensley (1990), stress relieving of nickel ranges from $425-870{ }^{\circ} \mathrm{C}$ and therefore, three different annealing conditions at 300, 500 and $700{ }^{\circ} \mathrm{C}$ were chosen. Corrosion rates of pure nickel for both non-heat treated and annealed samples were determined by using the Eurocell Tafel extrapolation technique with GRES-DC 105 software. The samples of pure nickel were characterised for tensile properties, a hardness morphology study and corrosion test.

Mechanical studies on the tensile and hardness properties of both non-heat treated and annealed samples of pure nickel were performed using an Instron 5585 Universal testing machine (UTM) with a test speed in the range of $0.01 \sim 500 \mathrm{~mm} / \mathrm{min}$. A micro Vickers hardness tester (MITUTOYO HM-200) was used to test all samples. For the Vickers test, both diagonals were measured and the average value was used to compute the Vickers hardness (HV). The hardness number is based on the surface area of the indent, divided by the applied force, giving hardness units of $\mathrm{kgf} / \mathrm{mm}^{2}$. X-Ray Diffraction was used to determine the crystal structure of the specimens and to identify changes in the lattice constant of both non-heat treated and annealed pure nickel. SEM and EDX were used to observe the materials morphology in macro and sub-micron 
ranges. In this report, EDX was used to confirm the composition of pure nickel in both the non-heat treated and annealed samples.

\section{RESULTS AND DISCUSSION}

\section{Hardness Analysis}

The hardness of non-heat treated and heat treated pure nickel was measured using a micro Vickers hardness tester. Pure nickel, annealed at temperatures of 300, 500 and $700{ }^{\circ} \mathrm{C}$, does not have a large difference in terms of its hardness value. Figure 1 shows the indentation of a diamond in contact with the surface of the sample. For non-heat treated pure nickel, the hardness value is $123.6 \mathrm{HV}$, whereas for samples annealed at 300,500 , and $700{ }^{\circ} \mathrm{C}$, the hardness value was $120.8,118.7$ and $120.5 \mathrm{HV}$, respectively, as shown in Figure 2.

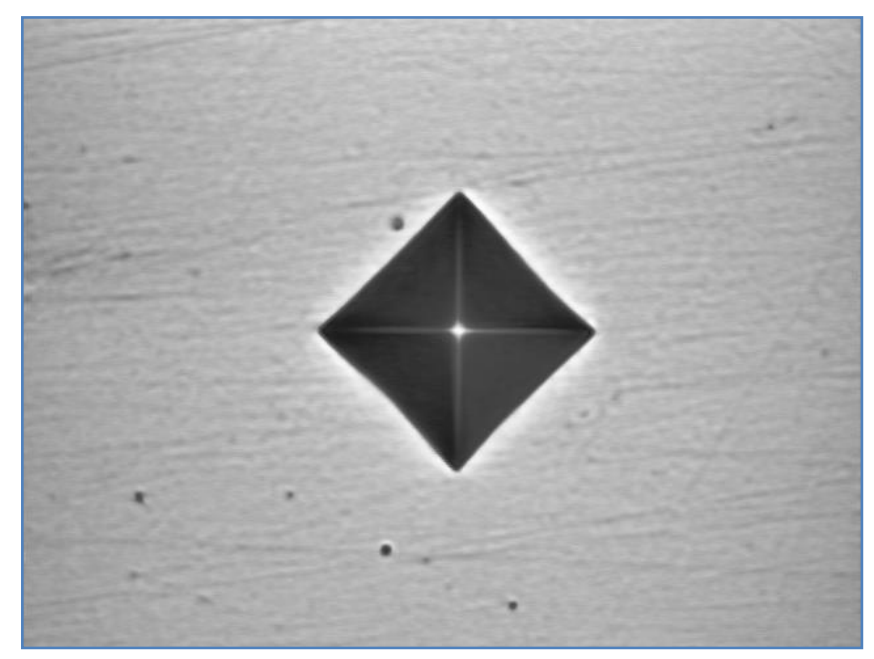

Figure 1. Indentation of diamond pyramid indenter with a $90^{\circ}$ angle between opposite faces. Image is magnified $50 \times$.

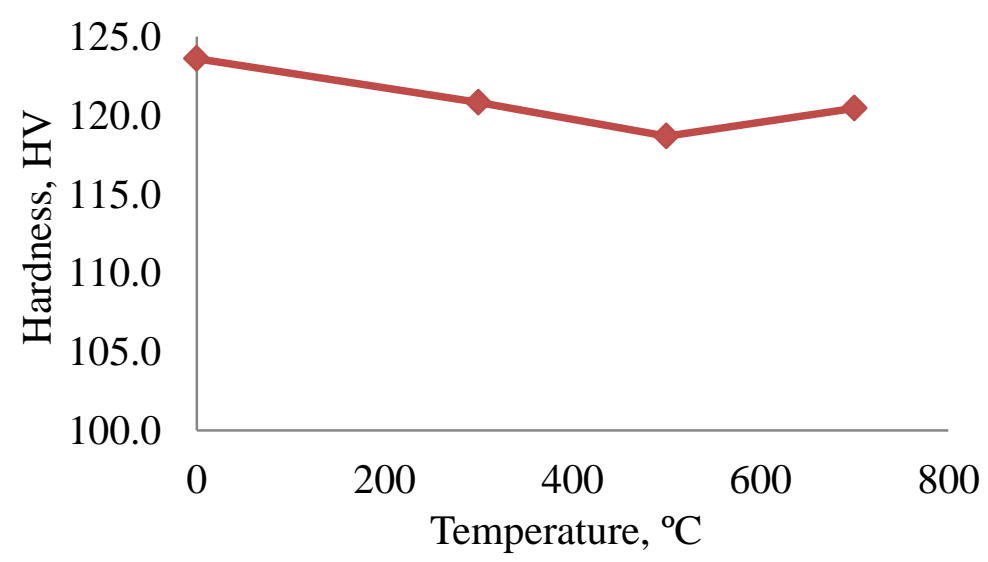

Figure 2. Hardness against annealing temperature.

The hardness of pure nickel with different annealing temperatures is shown in Table 1. There is no significant change in the hardness values of pure nickel with 
different annealing temperatures for 1 hour. The range of hardness values for pure nickel at different annealing temperatures is 118-125 HV. According to the results obtained by Neishi, Horita, and Langdon (2002), the hardness for equal-channel angular pressing (ECAP) of pure nickel (99.99\% purity), annealing at 1 hour decreased as the annealing temperature increased. Figure 2 shows the hardness value of ECAP of pure nickel $(99.99 \%)$. The hardness value of pure nickel decreases to $100 \mathrm{HV}$ as the annealing temperature increases. For an annealing temperature of $500{ }^{\circ} \mathrm{C}$, the hardness value of the sample is $118 \mathrm{HV}$, which is in good agreement with previous studies (Neishi et al., 2002).

Table 1. Hardness of pure nickel with different annealing temperature.

\begin{tabular}{ccccccc}
\hline \multirow{2}{*}{ Pure Nickel } & \multicolumn{7}{c}{ Hardness values (HV) } \\
& 1 & 2 & 3 & 4 & 5 & Average \\
\hline Non heat-treated & 120.9 & 127.7 & 139.3 & 111.8 & 118.4 & 123.6 \\
$300^{\circ} \mathrm{C}$ - annealed & 116.6 & 118.3 & 125.3 & 125.0 & 119.0 & 120.8 \\
$500^{\circ} \mathrm{C}$ - annealed & 120.8 & 127.5 & 109.5 & 122.3 & 113.4 & 118.7 \\
$700^{\circ} \mathrm{C}$ - annealed & 117.3 & 124.5 & 115 & 128.2 & 117.3 & 120.5 \\
\hline
\end{tabular}

\section{Tensile Analysis}

A tensile test was carried out to obtain the tensile stress-strain behaviour of both nonheat treated and annealed pure nickel. Table 2 shows the mechanical properties (ultimate tensile strength, Young's modulus and yield strength) of the pure nickel with different annealing temperatures. Figure 3 presents the ultimate tensile strength against different annealing temperatures of pure nickel. The ultimate tensile strength decreases as the annealing temperature increases. The highest ultimate tensile strength is 758.78 MPa measured for the sample heat treated at $300{ }^{\circ} \mathrm{C}$ and the lowest value is $368.07 \mathrm{MPa}$ measured for the annealed sample at $700{ }^{\circ} \mathrm{C}$. The yield strength at $0.2 \%$ offsets is determined by finding the intersection of the stress-strain curve with a line parallel to the initial slope of the curve, which intercepts the abscissa at $0.2 \%$.

Table 2. Mechanical properties of pure nickel with different annealed temperatures.

\begin{tabular}{ccccc}
\hline Pure nickel & $\begin{array}{c}\text { Ultimate tensile } \\
\text { strength, (MPa) }\end{array}$ & $\begin{array}{c}\text { Young's } \\
\text { Modulus ( GPa) }\end{array}$ & $\begin{array}{c}\text { Yield Strength } \\
(\mathrm{MPa})\end{array}$ & $\begin{array}{c}\text { Elongation, } \\
(\%)\end{array}$ \\
\hline Non heat-treated & 645.47 & 39.37 & 440 & 11.67 \\
$300^{\circ} \mathrm{C}$-annealed & 758.78 & 30.67 & 530 & 14.54 \\
$500{ }^{\circ} \mathrm{C}$-annealed & 525.30 & 15.07 & 350 & 17.80 \\
$700{ }^{\circ} \mathrm{C}$-annealed & 368.07 & 15.60 & 240 & 12.36 \\
\hline
\end{tabular}

Figure 4 presents yield strength against different annealing temperatures of pure nickel. The yield strength of $300{ }^{\circ} \mathrm{C}$ annealed pure nickel is higher than that of the nonheat treated pure nickel, the $500{ }^{\circ} \mathrm{C}$ annealed and the $700{ }^{\circ} \mathrm{C}$ annealed pure nickel. The yield strength is highest at $530 \mathrm{MPa}$ for the $300{ }^{\circ} \mathrm{C}$ annealed pure nickel and lowest at $240 \mathrm{MPa}$ for the $700{ }^{\circ} \mathrm{C}$ annealed pure nickel. The Young's modulus is a measure of the stiffness of the material. A stiff material with a high Young's modulus shows much 
smaller changes in dimension when the applied stress is relatively small and only causes elastic deformation (Askeland \& Phule, 2006).

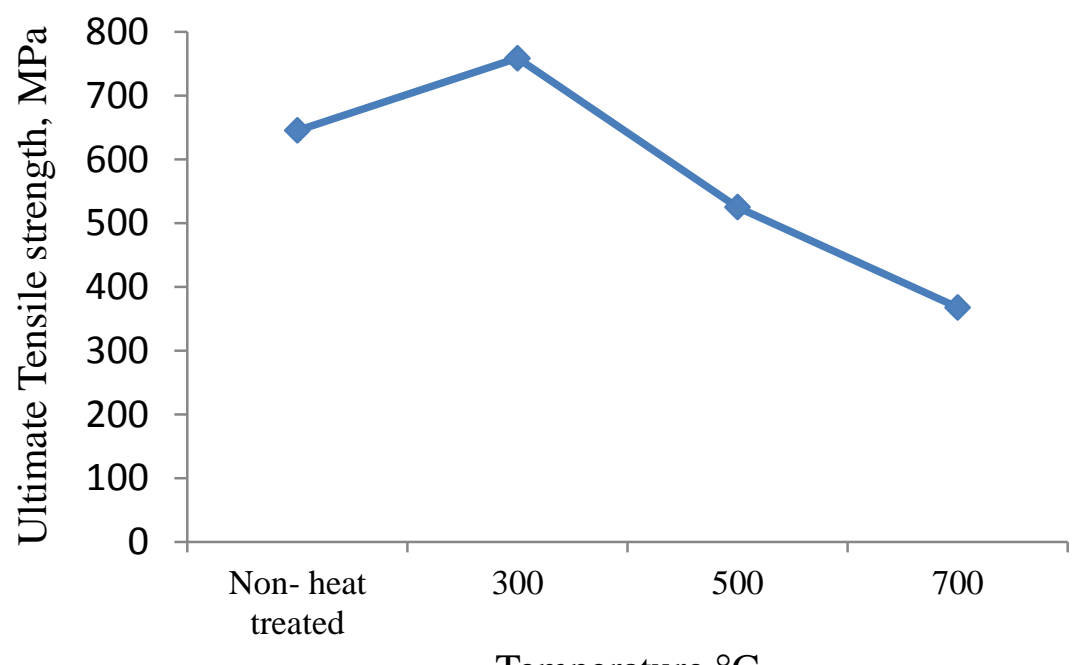

Temperature, ${ }^{\circ} \mathrm{C}$

Figure 3. Ultimate tensile strength against different annealing temperature of pure nickel.

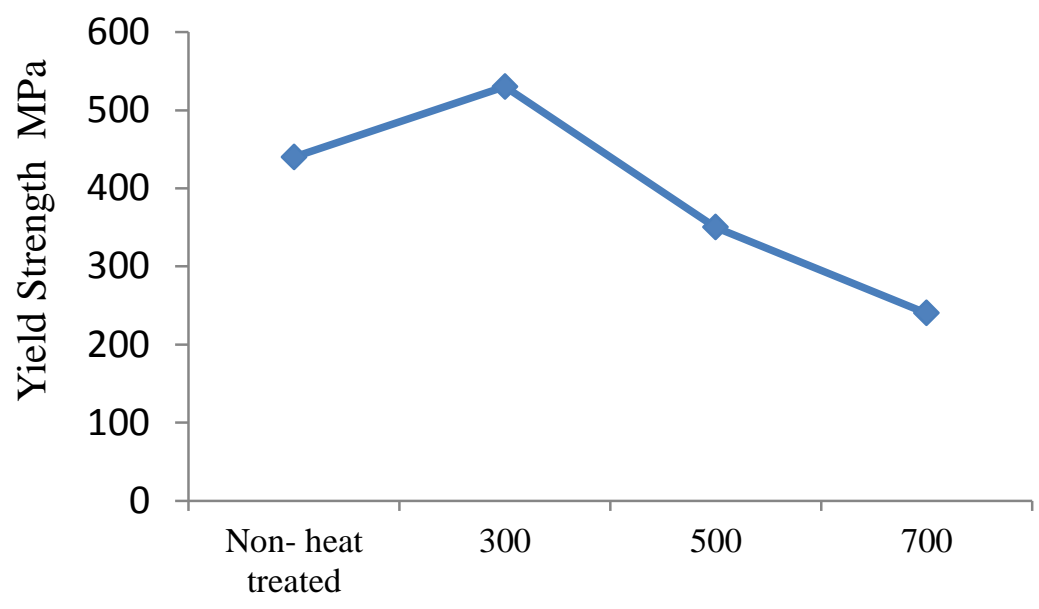

Temperature, ${ }^{\circ} \mathrm{C}$

Figure 4. Yield strength against different annealing temperature of pure nickel.

Figure 5 presents the Young's modulus against different annealing temperature of pure nickel. The Young's modulus of non-heat treated pure nickel is the highest compared with annealed pure nickel. This indicates that non-heat treated pure nickel has greater stiffness compared with annealed pure nickel. The yield strength of $300{ }^{\circ} \mathrm{C}$ annealed pure nickel is higher compared with the high strength steel used in the automotive industry. The yield strength and ultimate tensile strength of non-heat treated and 300 and $500{ }^{\circ} \mathrm{C}$ annealed pure nickel is higher than forming grade. However, the yield strength and ultimate tensile strength of non-heat treated and 300,500 and $700{ }^{\circ} \mathrm{C}$ annealed pure nickel are lower than for ultra-high-strength steel, titanium sheet, glassreinforced plastic and carbon fibre composite. The ultimate tensile strength of ultra- 
high-strength steel, titanium sheet, glass-reinforced plastic and carbon fibre composite is more than $924 \mathrm{MPa}$. The yield strength of ultra-high-strength steel, titanium sheet, glass-reinforced plastic and carbon fibre composite is more than $880 \mathrm{MPa}$. The cost of nickel $(\mathrm{MYR} / \mathrm{Kg})$ is higher than steel, aluminium and magnesium but lower than that of titanium alloy and composite. Therefore, pure nickel could act as an alternative automotive body material, replacing titanium and composite and in a few cases, steel.

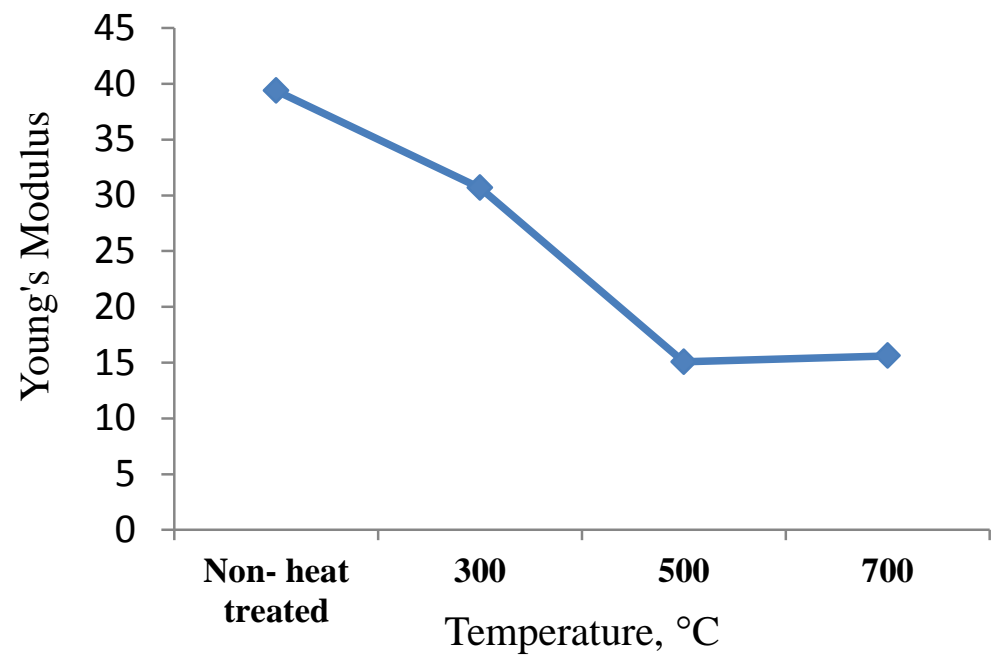

Figure 5. Young's modulus with different annealing temperature of pure nickel.

\section{Corrosion Test}

The Tafel extrapolation technique has been used to obtain the corrosion rate of nickel for various conditions of annealing temperatures. Figure 6 shows the corrosion of pure nickel for non-unannealed and annealed samples. The results of the corrosion analysis (corrosion current density and corrosion rate) using the Tafel extrapolation technique are tabulated in Table 3. There is no significant change in the corrosion rate of pure nickel at different annealing temperatures. The corrosion rate of $700{ }^{\circ} \mathrm{C}$ annealed pure nickel is the highest $(0.048 \mathrm{~mm}$ per year) compared with the others. The corrosion rate of both $300{ }^{\circ} \mathrm{C}(0.0385 \mathrm{~mm} /$ year $)$ and $500{ }^{\circ} \mathrm{C}(0.0266 \mathrm{~mm} /$ year $)$ annealed pure nickel is lower than that of non-heat treated pure nickel and $700{ }^{\circ} \mathrm{C}$ annealed pure nickel.

Table 3. Corrosion analysis by using Tafel Extrapolation technique.

\begin{tabular}{cccccc}
\hline Pure nickel & $\begin{array}{c}\text { Area in } \\
\text { contact, } \\
\mathrm{cm}\end{array}$ & $\begin{array}{c}\text { Density } \\
\left(\mathrm{g} / \mathrm{cm}^{3}\right)\end{array}$ & $\begin{array}{c}\text { Total } \\
\text { anodic } \\
\text { current, } \\
\mu \mathrm{A}\end{array}$ & $\begin{array}{c}\text { Corrosion } \\
\text { current } \\
\text { density, } \\
\mathrm{A} / \mathrm{cm}^{2}\left(\mathrm{i}_{\text {corr }}\right)\end{array}$ & $\begin{array}{c}\text { Corrosion rate } \\
\text { in } 3.5 \% \\
\mathrm{NaCl}(\mathrm{mm} / \text { year })\end{array}$ \\
\hline Non-heat-treated & 1.83 & 8.32 & 7.0 & 3.823 & 0.0440 \\
$300{ }^{\circ} \mathrm{C}$-annealed & 1.83 & 8.54 & 4.0 & 3.421 & 0.0385 \\
$500{ }^{\circ} \mathrm{C}$-annealed & 1.83 & 8.89 & 6.0 & 3.925 & 0.0466 \\
$700{ }^{\circ} \mathrm{C}$-annealed & 1.83 & 9.37 & 8.0 & 4.6852 & 0.0480 \\
\hline
\end{tabular}

Corrosion resistance of automotive body material is an important parameter when considering its expected lifetime and maintenance. Nickel has good corrosion 
resistance compared with aluminium, magnesium and iron. The rate of steel oxidation is higher and therefore, to improve the corrosion resistance of steel and to prolong automotive life, it is common to apply coated steel sheets to automotive body parts. There are various methods used for the protection of steel, such as zinc coatings, paint pre-treatments, electro-priming, wax injection and adhesives. According to Hayashi and Nakagawa (1994), the coated steel sheets have difficulty in press forming, such as surface damage of the plating layer, surface defects and unstable forming performance. Therefore, nickel is a good material for use as an alternative in automotive body parts due to it corrosion resistance.
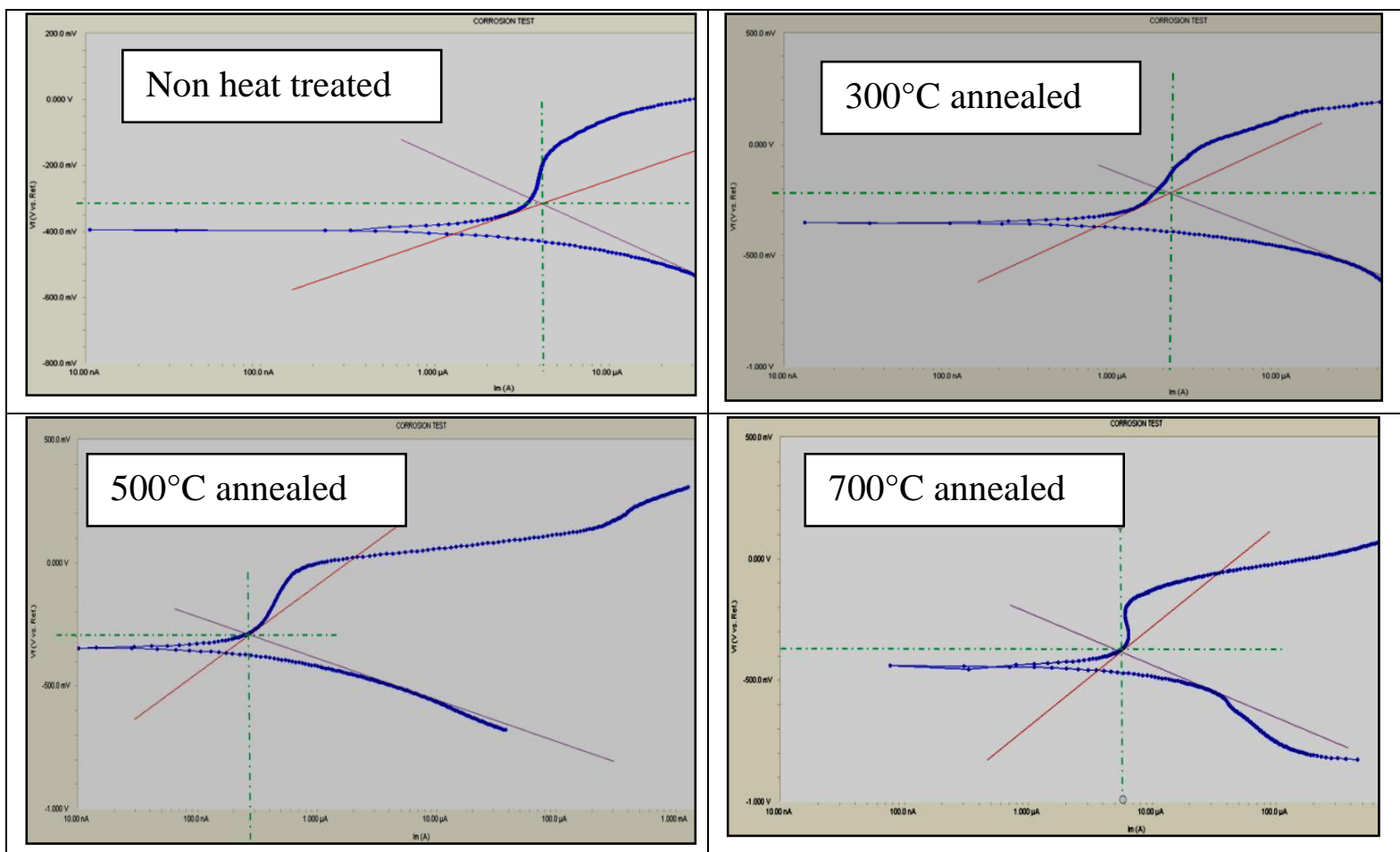

Figure 6. Tafel extrapolation of both non-heat treated and annealed nickel samples.

\section{Energy Dispersive X-Ray Analysis}

The purpose of using EDX is to identify the composition of both the non-heat treated pure nickel and the annealed pure nickel and the results are shown in Figure 7. It can be seen that the weight percentage and atomic percentage of non-heat treated and annealed pure nickel is not changed, which confirms that there are no impurities nor foreign elements present after heat treatment of the samples.

\section{X-Ray Diffraction Analysis}

The purpose of XRD is to identify the crystallographic changes of the non-heat treated and annealed pure nickel and the results are presented in Figure 8. By using the data obtained from XRD, the grain size of the pure nickel with different annealing temperatures can be calculated. The peak of pure nickel was determined from theoretical XRD lattice parameters, as shown in Table 4 with the comparison between 
the theoretical and experimental interplanar spacing of the non-heat treated pure nickel sample.

Table 4. Theoretical XRD lattice parameter of pure nickel.

\begin{tabular}{ccccccc}
\hline \multirow{2}{*}{ Pure nickel } & \multicolumn{2}{c}{ Interplanar spacing $d(\mathrm{dm})$} & Angle & $(h k l)$ & Intensity \\
\cline { 2 - 4 } & Theoretical & Experimental & $(2 \theta)$ & & & \\
\hline \multirow{3}{*}{ Ni Cubic, } & 0.2034 & 0.2020 & 44.505 & 11 & 1 & 100 \\
$a=0.3524 \mathrm{~nm}$ & 0.1762 & 0.1750 & 51.844 & 200 & 42 \\
& 0.1246 & 0.1242 & 76.366 & 22 & 0 & 21 \\
& 0.1062 & 0.1059 & 92.939 & 311 & 20 \\
& 0.1017 & 0.1015 & 98.44 & 22 & 7 \\
\hline
\end{tabular}

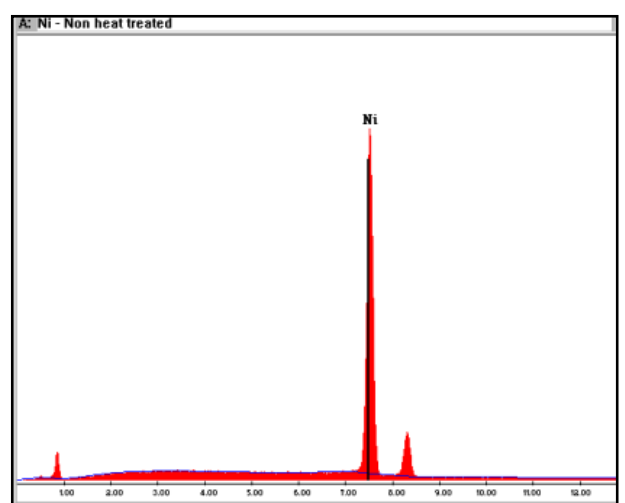

Non-heat -treated

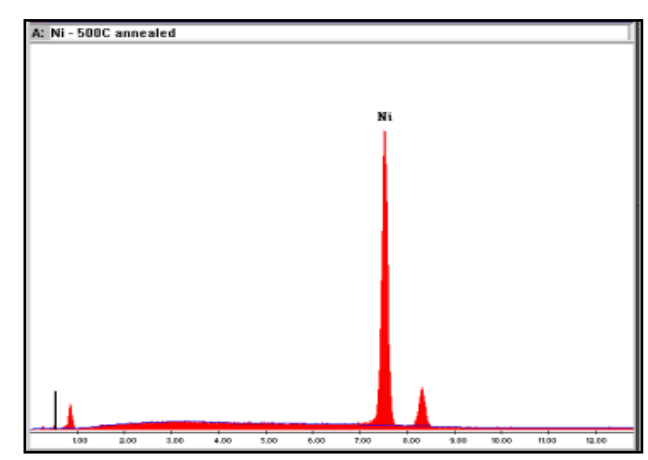

$500{ }^{\circ} \mathrm{C}$ annealed

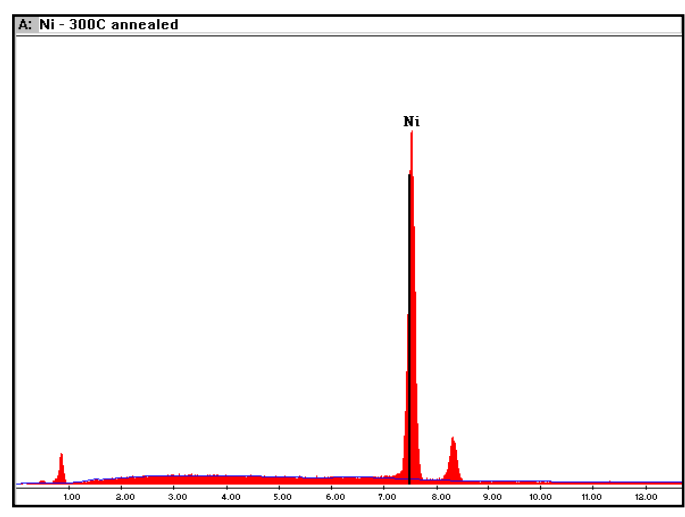

$300{ }^{\circ} \mathrm{C}$ annealed

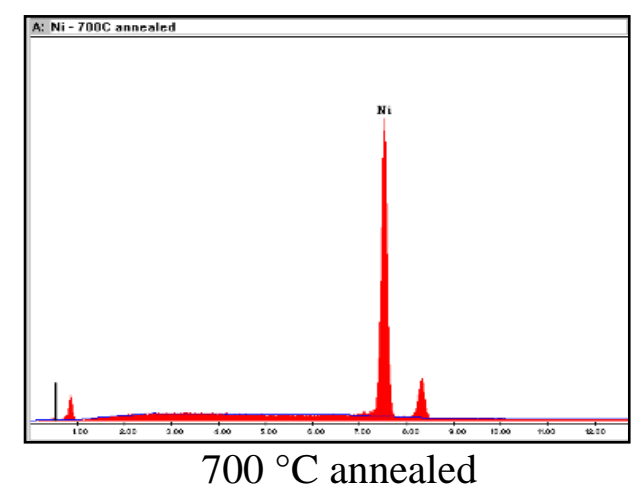

Figure 7. Compositional results obtained from EDX for non-heat treated and annealed pure nickel.

Table 5 shows the comparison lattice constant of both non-heat treated and annealed pure nickel in different peaks. The theoretical lattice constant for pure nickel is $0.3524 \mathrm{~nm}$. The lattice constant is calculated from Eq. (1).

$$
d_{h k l}=\frac{a}{\sqrt{h^{2}+k^{2}+l^{2}}}
$$

where: $a=$ Lattice constant; $d=$ Interplanar spacing, $\mathrm{nm} ;(h, k, l)=$ Miller indices. 


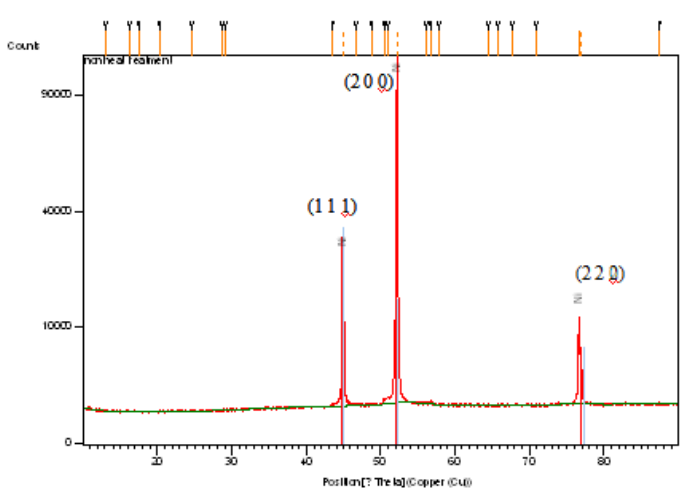

Non-Heat Treated

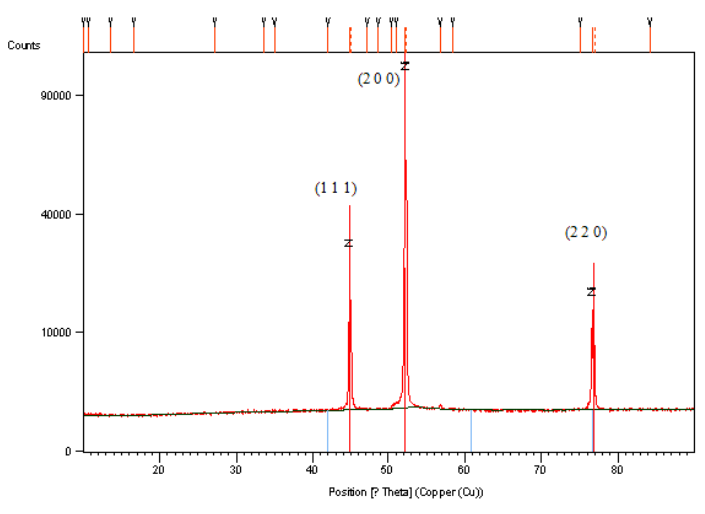

$500{ }^{\circ} \mathrm{C}$ annealed

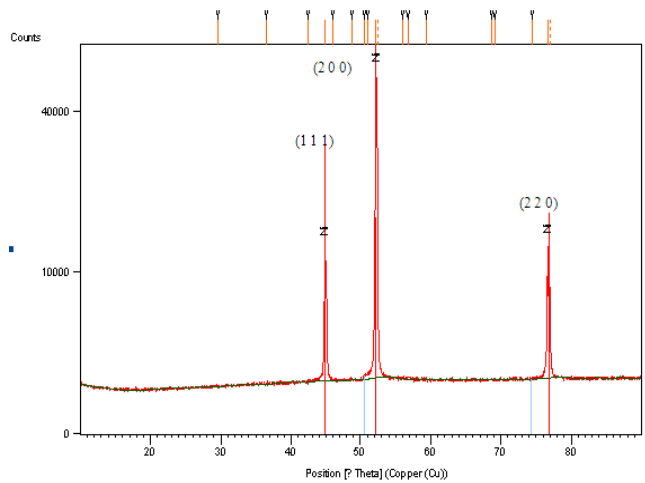

$300{ }^{\circ} \mathrm{C}$ annealed

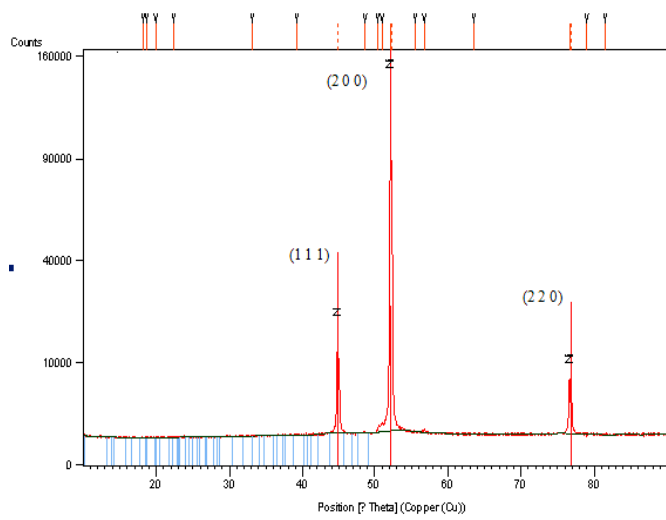

$700{ }^{\circ} \mathrm{C}$ annealed

Figure 8. Crystallographic results obtained from X-Ray diffraction.

Table 5. XRD lattice parameters comparison (taking the (111), (200) and (220) - peak as reference.

\begin{tabular}{cccc}
\hline Pure nickel & \multicolumn{3}{c}{ Lattice constant, $a$} \\
& $(111)$ & $(200)$ & $(220)$ \\
\hline Non-heat treated & 0.3503 & 0.3502 & 0.3512 \\
$300^{\circ} \mathrm{C}$-annealed & 0.3499 & 0.3500 & 0.3511 \\
$500^{\circ} \mathrm{C}$-annealed & 0.3498 & 0.3496 & 0.3510 \\
$700^{\circ} \mathrm{C}$-annealed & 0.3494 & 0.3492 & 0.3509 \\
\hline
\end{tabular}

The crystallography of pure nickel was confirmed by XRD and it is confirmed as face centred cubic with the lattice constant in the range of 0.3492 to $0.3512 \mathrm{~nm}$, which is almost the same as with the theoretical lattice constant, $0.3524 \mathrm{~nm}$. From Table 5 , it can be seen that the lattice constant of pure nickel decreases as the annealed temperature increases. The grain size of pure nickel is calculated according to Eq. (2).

$$
\text { Grain Size }=\frac{0.9 \lambda}{B \cos \theta}
$$

where: $\lambda=$ wavelength

$B=$ peak width at half maximum in radians

$\Theta \quad=\quad$ half of the reported peak centric 
Table 6 shows the range of grain sizes for both non-heat treated and annealed pure nickel. The grain size of annealed pure nickel increases as the annealing temperature increases. According to Xiao, Mirshams, Whang, and Yin (2001), the occurrence of abnormal grain growth in metals and alloys is generally related to the presence of a restraining force against grain growth. The typical restraining forces are second phase particles, free surface and crystallographic texture.

Table 6. The grain size range of non-heat treated and annealed pure nickel.

\begin{tabular}{cc}
\hline Nickel & Grain size range $(\mathrm{nm})$ \\
\hline Non heat-treated & $0.6-2.7$ \\
$300{ }^{\circ} \mathrm{C}$-annealed & $0.3-3.5$ \\
$500{ }^{\circ} \mathrm{C}$-annealed & $0.5-4.4$ \\
$700{ }^{\circ} \mathrm{C}$-annealed & $0.4-12.3$ \\
\hline
\end{tabular}

\section{CONCLUSIONS}

From XRD analysis, the lattice constant of non-heat treated and annealed pure nickel is in the range of 0.3492 to $0.3512 \mathrm{~nm}$, which is in good agreement with the standard value of pure nickel $(0.3524 \mathrm{~nm})$. The grain size of pure nickel gradually increases for both non-heat treated and its annealed counterparts. The hardness of annealed pure nickel does not show major changes, which is in the range of 118-124 HV and temperature change does not affect the hardness. The yield strength and ultimate tensile strength of annealed pure nickel decreases as the annealing temperature increases. For $500{ }^{\circ} \mathrm{C}$ annealed pure nickel, the elongation is more prominent than for other samples. Therefore, $500{ }^{\circ} \mathrm{C}$ annealed pure nickel is more ductile compared with the other samples. The corrosion rate of $700{ }^{\circ} \mathrm{C}$ annealed pure nickel is greater than for the others; the lowest corrosion rate is for $500{ }^{\circ} \mathrm{C}$ annealed pure nickel. By comparing the characteristics of both annealed and unannealed pure nickel with the current automotive material, the tensile strength of pure nickel is higher compared with aluminium, magnesium and some of the steels. Pure nickel is ductile and has good toughness with an FCC structure, which makes it suitable as an automotive body material because it can also absorb energy in the case of high-speed crashes. The cost of pure nickel is higher than steel but lower than some of the materials currently used for automotive body parts, such as titanium alloy and composites.

\section{ACKNOWLEDGEMENTS}

The work undertaken in this paper was supported by Universiti Teknikal Malaysia Melaka (UTeM) and MoHE with the FRGS grant (Project No. FRGS/2011/FKP/TK02/1 F00120).

\section{REFERENCES}

Askeland, D. R., \& Phule, P. P. (2006). The science and engineering of material. Toronto: Thomson, 183-223.

Cui, X. T., Wang, S. X., \& Hu, S. J. (2008). A method for optimal design of automotive body assembly using multi-material construction. Materials and Design, 29, 381-387. 
Davies, G. (2003). Materials for automobile bodies. Butterworth-Heinemann, pp. 61170.

Edwards, K. L. (2004). Strategic substitution of new materials for old: applications in automotive product development. Materials and Design, 25, 529-533.

Hayash, H., \& Nakagawa. T. (1994). Recent trends in sheet metals and their formability in manufacturing automotive panels. Journal of Materials Processing Technology, 46, 455-487

Klarstrom, D. L. (2001). The development of Haynes 230 alloy. Materials Design Approaches and Experiences, In: Zhao, J.C., Fahrmann, M. and Pollock, T. M. (Eds.), TMS 2001, pp. 297-307.

Kuroda, D., Kawasaki, H., Yamamoto, A., Hiromoto, S., \& Hanawa. T. (2005). Mechanical properties and microstructures of new $\mathrm{Ti}-\mathrm{Fe}-\mathrm{Ta}$ and $\mathrm{Ti}-\mathrm{Fe}-\mathrm{Ta}-\mathrm{Zr}$ system alloys. Materials Science and Engineering C, 25, 312-320

Lee, D. C., Woo, Y. H., Lee, S. H., \& Han, C. S. (2008). Design consideration of the nonlinear specifications in the automotive body. Finite Elements in Analysis and Design, 44, 851-861.

Neishi, K., Horita, Z., \& Langdon, T. G. (2002). Grain refinement of pure nickel using equal-channel angular pressing. Materials Science and Engineering A, 325, 5458.

Rebak, R. B., Dillman, J. R., Crook, P., \& Shawber, C. V. V. (2001). Corrosion behavior of nickel alloys in wet hydrofluoric acid. Materials and Corrosion, 52, 289-297.

Tillack, D. J., Manning, J. M., \& Hensley, J. R. (1990). ASM Handbook Volume 04: Heat Treating. OH: USA: ASM International, pp. 907-912.

Xiao, C. H., Mirshams, R. A., Whang, S. H., \& Yin, W. M. (2001). Tensile behavior and fracture in nickel and carbon doped nanocrystalline nickel. Materials Science and Engineering. A, 301(1), 35-43. 